\title{
CATARACTS IN GALACTOSAEMIA*
}

BY

\author{
F. D. MCAULEY
}

London

WHEN milk is taken by mouth, the lactose that it contains (breast milk contains a higher concentration than cow's milk) is hydrolysed by the enzyme lactase into its constituent monosaccharides, glucose and galactose, which are absorbed from the intestine, probably by a process of phosphorylation. The galactose, which is the most readily absorbed of the monosaccharides, is then taken to the liver by the portal circulation, where it is normally converted into glycogen by the hepatic cells.

Galactosaemia is a disorder of metabolism in which this conversion of galactose into glycogen is interrupted, and in consequence the blood level of the sugar rises, allowing a considerable quantity to appear in the urine. The basic cause of the disease is said to be a defective enzyme system in the liver, the exact nature of which is, as yet, unknown.

Clinical features of the disease are a failure to thrive, hepatomegaly, splenomegaly, albuminuria, jaundice, cataracts, and a low blood glucose level; mental retardation is a feature of long-standing cases. A familial tendency has been noted in some of the cases reported (Göppert, 1917; Bell, Blair, Lindsay, and Watson, 1950; Donnell and Lann, 1951; Townsend, Mason, and Strong, 1951; de Haas, 1951; Gorter, 1951; Ellenburg and Peterson, 1951).

The association of cataracts with galactosaemia was originally described by Mason and Turner† in a personal communication to Bruck and Rapoport (1945), who referred to it in a report of a case of their own.

\section{Case Reports}

Two further cases of galactosaemia are now reported, showing lens changes which regressed with treatment of the disease; a report on the general condition in each case is to be published later but the ocular changes deserve special comment.

Case 1.-A 12-day-old male infant was admitted to the Queen Elizabeth Hospital for Children, London, under the care of Dr. C. T. Potter.

He was not thriving normally, and was lethargic and jaundiced; the liver and spleen were enlarged. The urine constantly contained a substance which reduced Benedict's reagent and which was later identified as galactose, confirmed by paper partition chromatography. Glucose tolerance was normal but a galactose tolerance test showed a grossly abnormal curve.

Ocular Examination.-At the age of 4 weeks a small opacity was seen in each lens which was recorded as being " post-capsular in one eye and centrally placed in the other". He was started on a lactose-free diet 4 days later, after which his general condition began to improve.

* Received for publication July 3, 1953.

$\dagger$ Mason and Turner (1935) had not recorded the presence of cataracts in this case in their original description of it. 
At 6 months of age it was noted that his eyes failed to follow a light. Ophthalmological examination at 8 months showed a left divergent strabismus of $35^{\circ}$ with good fixation in either eye, the right apparently being the dominant eye. The pupils and movements were normal. On ophthalmoscopy a central disc-shaped opacity was observed in the right eye which appeared to be in the region of the posterior pole. The left lens showed punctate opacities.

At $9 \frac{1}{2}$ months binocular fixation had developed but an exophoria was manifested on occlusion. The opacity in the right lens remained unchanged while the left lens appeared clear. At the age of 16 months, the ocular condition was essentially the same, though the faint opacity in the right lens was still present.

Case 2.-A male infant aged 4 weeks was admitted to the Westminster Hospital, under the care of Dr. Ian M. Anderson on 9 September, 1952. He was a small, wizened, and lethargic baby with hepatomegaly and splenomegaly; jaundice was absent on admission but had been noted during the first week of neo-natal life. The urine contained a substance which reduced Benedict's reagent. One week later, the blood sugar, in a sample taken 2 hours after a feed, was $280 \mathrm{mg}$. per cent. ; specific tests, including paper partition chromatography, revealed the excess sugar to be galactose; in a specimen taken after a 4-hour fast, galactose was present to the extent of $205 \mathrm{mg}$. per cent., and the glucose level was $52 \mathrm{mg}$. per cent.

Ocular Examination.-At the age of 6 weeks fixation had not yet developed, but the eyes appeared to be in alignment. The pupils and movements were normal. With the ophthalmoscope faint striate opacities were seen to radiate from the clear central area of both lenses; these appeared to be situated anteriorly and simulated a wrinkling in the lens capsules (See Figure). Nothing abnormal was noted in the fundi.
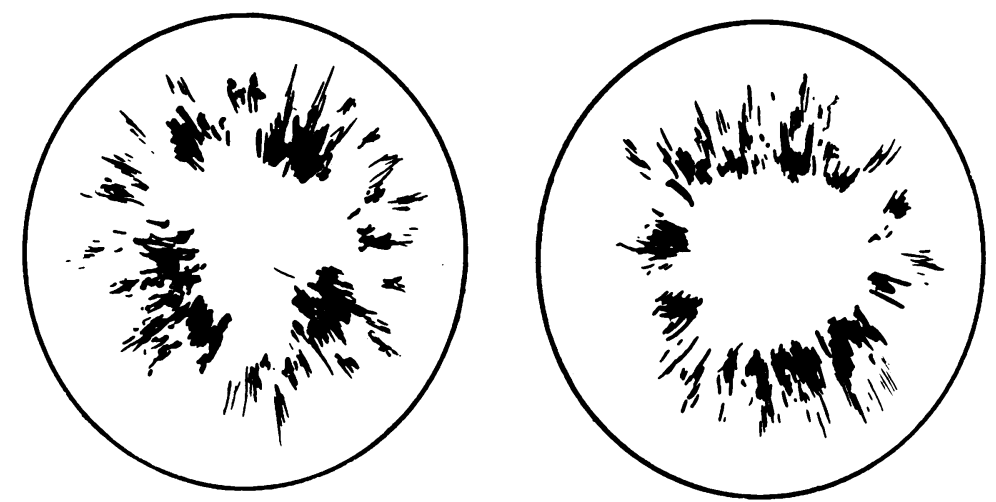

FIGURE.-Ophthalmoscopic appearance of the lenses at 6 weeks.

On the following day the patient was started on a lactose-free diet, whereupon the urine became sugar-free and the blood sugar level fell rapidly to $90 \mathrm{mg}$. per cent. Ophthalmoscopic examination one week later showed no evidence of the striate opacities which had previously been noted.

When he was 7 weeks old there appeared to be a marked difference in refraction between the axial and peripheral portions of both lenses which made observation of the fundi difficult. This effect was still present when he was examined 3 weeks later, but had disappeared by the time he was 14 weeks old. Subsequent monthly observations revealed apparently clear lenses.

At 7 months of age, however, a very faint central opacity was discovered in the left lens which appeared to be situated at the posterior pole. Six months later this faint opacity was still present but the right lens remained clear. On cover test a small angle of exophoria with rapid recovery was manifested; this had not previously been noted. 


\section{Discussion}

Cases previously Reported.-Of 33 cases so far reported in full, lenticular changes were noted in 21.

The reports of von Reuss (1908), Göppert (1917), and Unshelm (1934) do not mention examination of the eyes. Of the remainder, one case was diagnosed on the 8th day and treatment was instituted promptly, thus probably preventing the onset of lens changes (Bell and others, 1950). The patient of $\frac{\bar{v}}{\vec{v}}$ Maris and Valcke (1953) was stated to have a fluffy appearance of the lens $\stackrel{\circ}{\circ}$ on the 15th day although cataracts were said to be absent. In another case $\%$ it was stated that "the optic fundi on examination were not unusual" $\vec{\circ}$ (DuShane and Hartman, 1951). The diagnosis of galactosaemia in one of $\vec{\omega}$ the three cases of Townsend, Mason, and Strong (1951), which were free $\frac{\partial}{\circ}$. from lens changes, was made shortly after birth; the other two were diag- $\stackrel{\omega}{\omega}$ nosed at 6 weeks and 5 months of age respectively. This last case appears to $\overrightarrow{.}$ be the oldest recorded untreated patient who was free from cataractous o changes. In a case diagnosed at 2 months of age in which the patient died before treatment was begun, cataracts were not demonstrated in vivo or $\stackrel{3}{-}$ post mortem (Edmonds, Hennigar, and Crooks, 1952).

Ellenburg and Peterson (1951) refer to subsequent operative treatment of the lenses of the cases originally recorded by Norman and Fashena (1943) and Mellinkoff, Roth, and McLaggan (1945), thus suggesting that lens chano ges did occur in these cases.

The evidence therefore indicates that cataract may be regarded as a constant feature of untreated cases, the oldest untreated case with clear lenses being the 5-month-old child reported by Townsend and others (1951). It is also suggested that disturbance of the osmotic equilibrium between the lens and the aqueous is the major factor in the production of these changes.

Histological Changes.-The occurrence of cataractous changes in rats fed on galactose or on lactose is an accepted phenomenon (Mitchell and Dodge, 1935; Yudkin and Arnold, 1935; Bellows, 1936; Bellows and Rosner, 1937; Gifford and Bellows, 1939; Mitchell and Cook, 1940; Yudkin and Geer, 1940).

The histological changes present in the lenses of white rats fed on a diet containing 50 per cent. galactose, but in which all known essential food factors were included, were described by Gifford and Bellows (1939). They found that the degeneration affected the young fibres near the equator, N following the course of these fibres towards the anterior and posterior poles. $N$ There was a layer of unaffected tissue next to the capsule which suggested $\underset{\omega}{\widetilde{N}}$ that the youngest fibres are not affected, or that, as is more likely, new fibres continue to be laid down from the most posterior cells of the capsular epithelium more rapidly than degeneration becomes apparent. Changes in the capsule and in the capsular epithelium were said to occur quite late. The nucleus and a layer of cortex ensheathing it were apparently intact in all stages except when the cataract was in the mature state. 
Animals which showed early cataractous changes and which were then fed on a normal diet, leading to complete disappearance of opacities as observed ophthalmoscopically, did, however, have the remains of degenerate fibres just peripheral to the nucleus. These areas of degeneration had been compressed towards the centre of the lens by a layer of newly formed, apparently normal, fibres. Gifford and Bellows state that, in their observations, the nucleus was the last part of the lens to be affected.

Metabolic Studies.-Disturbance of the glutathione content has been put forward as a causal factor in the cataractogenesis. Rosner, Farmer, and Bellows (1938) state that the glutathione content of the lens at birth approximates to that of the blood, but that in the first few days of life this is rapidly augmented in order to meet the mounting metabolic and growth demands of the lens. This increase continues until the fourth month of life after which the amount present in the lens declines slowly. It appears that the variation of glutathione content is mainly confined to the cortex. When animals are fed on galactose the glutathione content in the lens diminishes, rapidly in the beginning and more slowly as feeding is continued. This depletion is unlikely to be due to loss through the lens capsule, because the capsule has been shown to be less permeable to glutathione in the presence of galactose (Bellows and Rosner, 1938). It is suggested that the decreased glutathione content is due to an upset of metabolism as a result of a failure of anabolites to enter into the lens, and/or of metabolites to escape from it. A return to normal transparency is accompanied by a resumption of its normal concentration of glutathione, but the opaque portion of the lens is unable to recover its glutathione. It is interesting to note that Bellows and Shoch (1950), in their experiments on diabetes induced by feeding alloxan to rats, found that if diabetes did not develop there was no fall in the lenticular glutathione. They also noted that the alloxan did not lead directly to a decrease in the quantity of glutathione, since this did not occur until at least $72 \mathrm{hrs}$ after all the alloxan had been excreted and detoxified. It would appear therefore that depletion of the lenticular glutathione is not necessarily a precursor of the cataractous changes occurring in these cases.

The blood glucose level is lowered in galactosaemia; it has therefore been suggested that hypoglycaemia may be a factor in the cataractogenesis. This is unlikely to be the case, since cataracts are not ordinarily seen in spontaneous hypoglycaemia although a 6-year-old boy in the care of the ophthalmic department of Westminster Hospital for bilateral cataracts has spontaneous hypoglycaemia, and Grotts and Arnold (1949) have reported cataracts in two cases of functional hypoglycaemia in children.

That the aqueous concentration of glucose varies directly with that of the blood, has been shown by the intravenous injection of glucose (Duke-Elder, 1927), by the injection of insulin (Ohkuni, 1924), and by any condition in which the sugar content of the blood is altered (Dieter, 1925). On the other hand, Sasaki (1938) found that the concentration of simple sugars in the 
cataractous lenses of rats fed on galactose did not differ from that in the normal lens, and that the aqueous level of galactose was equivalent to its blood concentration. Bellows and Chinn (1941) were able to produce visible lenticular changes in dogs and rats within 20 to $30 \mathrm{~min}$. by the intravenous injection of hypertonic solutions of various substances including sodium chloride, sodium lactate and galactose; these changes regressed when the injections were discontinued. They found that there was no change in the amount of glutathione, ascorbic acid, or non-protein nitrogen in the lenses made cataractous by the intravenous injection of sodium chloride, but that the potassium content had increased by 13 per cent. Patterson (1953) contends that the cataractous changes occuring in conjunction with hyperglycaemia, galactosaemia, and probably with excess xylose arise solely as a result of the high blood level of the carbohydrate concerned. By the application of the laws based on the classical experiments of Pfeffer (1877) and Avogadro (1811), it would not be unreasonable to presume that osmosis may play a large part in the production of the lens changes occurring in galactosaemia.

The ophthalmoscopic appearances in Case 2 before the institution of treatment were suggestive of a dehydrated lens, whereas those seen 1 week and 4 weeks later might have been simulated by a tumescent lens. A possible explanation of this would be a swing over from an aqueous with a high sugar concentration to one with a low concentration, due to depletion of the galactose content and the temporary persistence of the low glucose level.

If these changes were in fact due to tumescence and dehydration of the lens, an appropriate change of refraction might be expected which could readily be determined by retinoscopy. Indeed Weekers (1941) found that myopic changes were induced by feeding galactose to animals, and were followed by the onset of hypermetropia when the galactose was stopped.

Similar phenomena may occur in diabetes mellitus where variability in the state of the refraction occurs with different blood sugar levels (Duke-Elder, 1949). The difference in the rate of onset of lens changes in galactosaemia from that seen in diabetes may be explained by the relative ages of the lenticular fibres when subjected to the effects of the abnormal aqueous. It has been shown that lenticular changes in rats on a galactose diet develop most readily in young rats, and this may indicate that the young lens is more easily injured by chemical changes in the surrounding medium (Mitchell and Dodge, 1935).

\section{Summary}

(1) Two cases of infantile cataract occurring in galactosaemia are described. The regression of the opacities on elimination of excess galactose from the blood-stream is noted.

(2) A possible osmotic mechanism for the production of the lens changes is discussed and a suggestion is made that retinoscopy may be of some value in determining the state of tension within the lens capsule in such cases. 
I wish to record my thanks to Dr. C. T. Potter and to Dr. Ian M. Anderson for permission to refer to their records of the two cases reported, to Mr. E. F. King and Mr. P. D. Trevor-Roper for much helpful advice in the preparation of this paper, and to the Medical Illustration Department at the Institute of Ophthalmology, London, for the drawing of the lenses.

\section{REFERENCES}

Avogadro (1811). Cited by Kleiner (1948).

Bell, L. S., Blair, W. C., Lindsay, S., and Watson, S. J. (1950). J. Pediat., 36, 427.

Bellows, J. G. (1936). Arch. Ophthal., Chicago, 16, 762. and CHINN, H. (1941). Ibid., 25, 796. and Rosner, L. (1937). Amer. J. Ophthal., 20, 1109. (1938). Arch. Ophthal., Chicago, 20, 80. and Sносн, D. E. (1950). Amer. J. Ophthal., 33, 1555.

Bruck, E., and RAPOPORT, S. (1945). Amer. J. Dis. Child., 70, 267.

DIETER, W. (1925). Arch. Augenheilk., 96, 179.

Donnell, G. N. and LanN, S. H. (1951). Pediatrics, 7, 503.

DUKE-ELDER, S. (1927). Biochem. J., 21, 66. (1949). "Text-book of Ophthalmology", vol. 4, p. 4364. Kimpton, London.

DuShane, J. W., and Hartman, E. E. (1951). Pediatrics, 7, 679.

Edmonds, A. M., Hennigar, G. R., and Crooks, R. (1952). Ibid., 10, 40.

Ellenburg, L. L., and Peterson, J. C. (1951). Amer. Practit., 2, 602.

GIFFORD, S. R., and Bellows, J. (1939). Arch. Ophthal., Chicago, 21, 346.

GÖPPERT, F. (1917). Berl. Klin. Wschr., 54, 473.

GorTer, E. (1951). Arch. Dis. Childh., 26, 271.

GrotTs, B. F., and ARnold, J. H. (1949). Arch. Pediat., 66, 462.

HAAS, P. K. DE (1951). Arch. Dis. Childh., 26, 272.

KLEINER, I. S. (1948). " Human Biochemistry ", 2nd ed., p. 34. Kimpton, London.

LoPresti, J. M., Itani, A., and Rice, E. C. (1952). Clin. Proc. Child. Hosp., Wash., 8, 233.

Maris, L., and VAlCKe, J. (1953). Arch. franç. Pédiat., 10, 36.

Mason, H. H., and Turner, M. E. (1935). Amer. J. Dis. Child., 50, 359.

Mellinkoff, S., Roth, B., and Maclaggan, J. (1945). J. Pediat., 27, 338.

Mitchell, H. S., and CooK, G. M. (1940). Proc. Soc. exp. Biol., N.Y., 43, 85. , and DODGE, W. M. (1935). J. Nutr., 9, 37.

Norman, F. A., and Fashena, G. J. (1943). Amer. J. Dis. Child., 66, 531.

OHKUNI (1924). Med. J. Japan, 43, (9). Quoted by Duke-Elder, S. (1938). “Text-book of Ophthalmology ", vol. 1, p. 443. Kimpton, London.

Patterson, J. W. (1953). Amer. J. Ophthal., 36, 143.

Pfeffer, W. (1877). Cited by Kleiner (1948).

Reuss, A. von. (1908). Wien. med. Wschr., 58, 799.

Rosner, L., Farmer, C. J., and Bellows, J. (1938). Arch. Ophthal., Chicago, $20,417$.

SASAKI, T. (1938). v. Graefes Arch. Ophthal., 138, 351.

Townsend, E. H. JnR., Mason, H. H., and Strong, P. S. (1951). Pediatrics, 7, 760.

UNSHELM, E. (1934). Dtsch. med. Wschr., 60, 633.

WeEkERS, R. (1941). Thèse, Liége. Quoted by Duke-Elder, S. (1949). " Text-book of Ophthalmology ", vol. 4, p. 4365. Kimpton, London.

Yudkin A. M., and ARnold, C. H. (1935). Arch. Ophthal., Chicago, 14, 960.

-, and GEER, H. A. (1940). Ibid., 23, 28.

\section{ADDITIONAL BIBLIOGRAPHY}

Bray, P. T., IsaAC, R. J., and Watkins, A. G. (1952). Arch. Dis. Childh., 27, 341

EnNs, J. H. (1951). Amer. J. Ophthal., 34, 1268.

Falls, H. F., Lowrey, G. H., and ANDERSON, W. C. JNR. (1951). I Ibid., 34, 1271.

FANCONI, G. (1933). Jb. Kinderheilk., 138, 1.

Goldbloom, A., and Brickman, H. F. (1946). J. Pediat., 28, 674.

GoldsteIn, E. O., and ENNIS, J. M. (1948). I Ibid., 33, 147.

Greenman, L., and Rathbun, J. C. (1948). Pediatrics, 2, 666.

Patz, A. (1953). Amer. J. Ophthal., 36, 453.

ReITER, C. and LASKY, M. A. (1952). Ibid., 35, 69.

STEINER, M. M. (1953). Ibid., 36, 841 . 